EXTENDED REPORT

\title{
Characterisation of cartilage intermediate layer protein (CILP)-induced arthropathy in mice
}

\author{
Z Yao, H Nakamura, K Masuko-Hongo, M Suzuki-Kurokawa, K Nishioka, T Kato
}

Ann Rheum Dis 2004;63:252-258. doi: 10.1136/ard.2003.008045

See end of article for authors' affiliations

....................

Correspondence to: Professor T Kato, Arthritis Research Centre, Institute of Medical Science, St Marianna University School of Medicine, 2-161 Sugao, Miyamae-ku, Kawasaki, Kanagawa 216-8512, Japan; t3kato@marianna-u.ac.jp

Accepted 27 May 2003

\begin{abstract}
Objectives: To characterise cartilage intermediate layer protein (CILP)-induced arthropathy in mice. Methods: The first and second halves of the nucleotide triphosphate pyrophosphohydrolase (NTPPHase) non-homologous region of human CILP were prepared as recombinant proteins ( $\mathrm{Cl}$ and $\mathrm{C} 2$, respectively), including three overlapping fragments of $\mathrm{C2}$ (C2F1, C2F2, and C2F3). C57BL/6 mice were immunised with these proteins to induce arthritis. In addition, a separate group of mice were immunised repeatedly with the mixture of $\mathrm{Cl}$ and $\mathrm{C} 2$ to see the effect of chronic immunisation. Arthritis developed in the mice, and cellular and humoral immune responses against CILP were analysed.

Results: Immunisation with $\mathrm{C} 2$ and with the mixture $\mathrm{C} 2 \mathrm{~F} 1 / \mathrm{C} 2 \mathrm{~F} 2 / \mathrm{C} 2 \mathrm{~F} 3$ caused the severest arthritis to develop in mice. Immunisation with one of $\mathrm{C1}$, C2F1, C2F2, or C2F3 caused milder arthritis, even though each of the fragments carried T cell epitopes. Immunisation either with $\mathrm{C} 1$ or $\mathrm{C} 2$ alone evoked cellular and humoral immune responses to both the $\mathrm{C} 1$ and $\mathrm{C} 2$ proteins. Further, the repeated immunisation with the $\mathrm{Cl} / \mathrm{C} 2$ mixture caused tendon calcification and bone irregularity, together with decreased NTPPH activity. Conclusions: The results show that multiple T cell epitopes are needed for the development of CILP-induced arthritis, and present the characteristic new model of mild arthropathy accompanied by extra-articular calcifications. An immune response to putative murine CILP/NTPPH may be involved in the ectopic calcifications in the arthritic mice.
\end{abstract}

E xtracellular matrix of the cartilage is mainly composed of type II collagen and proteoglycans. Autoimmunity to such major components of the cartilage has been shown to cause severe and acute destructive polyarthritis in animals, such as type II collagen-induced arthritis (CIA) ${ }^{12}$ and proteoglycan core protein-induced arthritis.-5 They have been investigated, in part, as a model of rheumatoid arthritis (RA) in humans. However, it is not fully understood whether autoimmunity to other minor components of cartilage causes such destructive arthritis as RA to develop. Recently, immunisation of mice with a cartilage derived chitinase family protein human cartilage glycoprotein 39 (HC gp39) was reported to develop severe polyarthritis, ${ }^{6}$ whereas immunisation with YKL-39, a similar cartilage related protein homologous to HC gp39, develops only mild arthritis. ${ }^{7}$ These findings indicate that the characteristics of immune mediated arthritis/ arthropathy depend on the individual antigens immunised.

Cartilage intermediate layer protein (CILP) was cloned as a cartilage related protein which resides in the middle layer of the cartilage matrix, with a homologous region to porcine nucleotide triphosphate pyrophosphohydrolase (NTPPHase) in its carboxyl terminal half. ${ }^{89}$ It has been suggested that the CILP/NTPPH might participate in extracellular inorganic pyrophosphate (PPi) production. ${ }^{10}$ Expression of CILP is reported to be up regulated during aging $^{811}$ and also in patients with the early stages of osteoarthritis. ${ }^{89}$ We recently reported that CILP was recognised as an autoantigen in patients with osteoarthritis and RA, and that immunisation of mice with recombinant CILP proteins developed mild but chronic polyarthritis. ${ }^{12}$

In this present study we attempted to characterise the arthropathy induced by CILP immunisation more extensively.

\section{MATERIALS AND METHODS}

Mice

Female 8-10 week old C57BL/6 mice were obtained from Nippon SLC Inc (Tokyo, Japan). Animal care was in accordance with the institutional guidelines.

\section{Preparation and isolation of recombinant CILP proteins}

As previously described, complementary DNA fragments that encoded the first half $\left(\mathrm{CDNA}^{\mathrm{Cl}}\right)$ and the second half $\left(\mathrm{CDNA}^{\mathrm{C} 2}\right)$ of the non-NTPPHase homologous region of CILP were obtained from mRNA of human articular chondrocytes. ${ }^{12}$ The $\mathrm{C} 2$ region was further divided into three regions (C2F1: 396 bp, C2F2: 399 bp, C2F3: 35l bp), and their respective cDNA fragments were obtained from $\mathrm{CDNA}^{\mathrm{C} 2}$ (fig l).

Production and purification of the CILP- $\beta$ Gal fusion proteins and the CILP-MBP fusion proteins were performed as described previously. ${ }^{13}{ }^{14}$ Briefly, each of the cDNA fragments that encode the $\mathrm{C} 1, \mathrm{C} 2, \mathrm{C} 2 \mathrm{~F} 1, \mathrm{C} 2 \mathrm{~F} 2$, and $\mathrm{C} 2 \mathrm{~F} 3$ regions were subcloned into plasmid expression vectors pTEX-eHis, which produced $\beta$-galactosidase $(\beta \mathrm{Gal})$ fusion proteins or into pMAL-eHis, which produced MBP fusion proteins, respectively.

\section{Induction of arthritis}

Fifty micrograms each of the single or mixed CILP- $\beta$ Gal fusion proteins was mixed with Freund's incomplete adjuvant (FIA) at $1: 1$ and injected into the right footpad of eight mice subcutaneously. Eight control mice received the same amount of the fusion partner of $\beta \mathrm{Gal}$ alone with FIA. After 14 days the mice were immunised again with the same amounts of the protein subcutaneously into the root of the

\footnotetext{
Abbreviations: BSA, bovine serum albumin; CIA, collagen-induced arthritis; CILP, cartilage intermediate layer protein; ELISA, enzyme linked immunosorbent assay; FCA, Freund's complete adjuvant; FIA, Freund's incomplete adjuvant; $\mathrm{HC}$ gp, human cartilage glycoprotein; MBP, maltose binding protein; NTPPHase, nucleotide triphosphate pyrophosphohydrolase; OD, optical density; PBST, phosphate buffered saline-Tween-20; PPi, inorganic pyrophosphate; RA, rheumatoid arthritis; SDS-PAGE, sodium dodecyl sulphate-polyacrylamide gel electrophoresis; $\mathrm{SI}$, stimulation index
} 
A

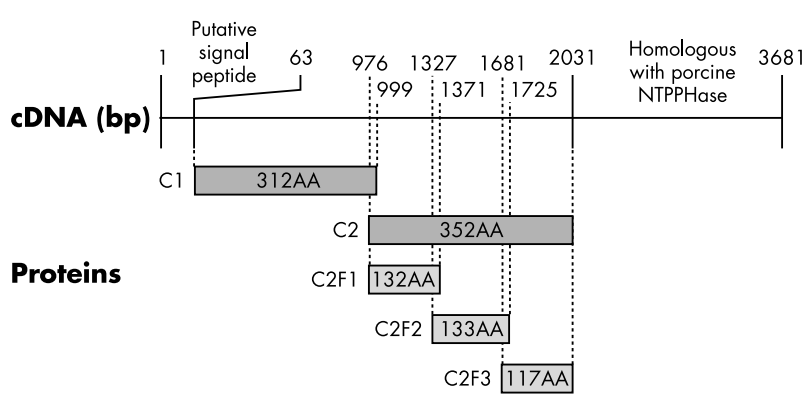

B

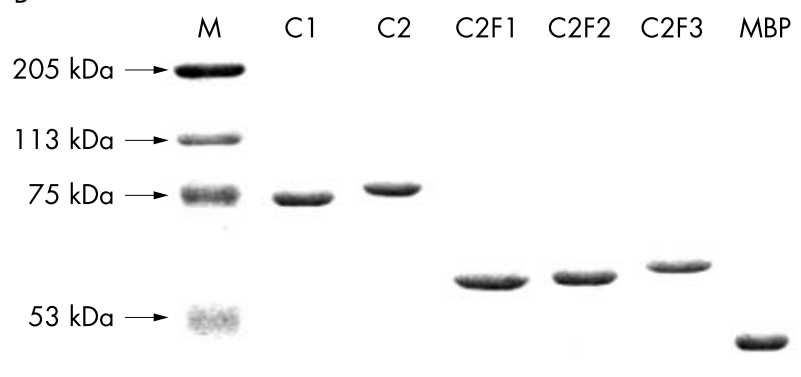

$34 \mathrm{kDa} \longrightarrow$

Figure 1 Recombinant CILP proteins used in this study. (A) Scheme showing the human CILP and recombinant CILP proteins prepared in this study. The first and second halves of the NTPPHase non-homologous region of the human CILP molecule (C1 and C2) and three regions that overlapped and covered the $\mathrm{C} 2$ region (C2F1, C2F2, and C2F3) were prepared as fusion proteins. (B) Recombinant CILP proteins produced as a maltose binding protein (MBP) fusion protein. Each of the $\mathrm{Cl}, \mathrm{C2}, \mathrm{C2F1}, \mathrm{C} 2 \mathrm{~F} 2$, and $\mathrm{C} 2 \mathrm{~F} 3$ regions was expressed as an MBP fusion protein. Purified protein samples were separated by sodium dodecyl sulphate-polyacrylamide gel electrophoresis (SDS-PAGE), transferred onto a nitrocellulose membrane, and stained with Ponceau-S.

tail. Further, as a separate experiment, a mixture of C1- $\beta$ Gal and $\mathrm{C} 2-\beta \mathrm{Gal}$ was used for repeated immunisations. Briefly, eight mice were immunised with $50 \mu \mathrm{g}$ of the mixture with an equal weight of Freund's complete adjuvant (FCA; SigmaAldrich, USA) intracutaneously, and this was then followed by four boosting immunisations on the root of the tail with $50 \mu \mathrm{g}$ of the same proteins using FIA on days 7, 28, 49, and 70 .

\section{Scoring of arthritis}

The incidence of arthritis was assessed daily. Clinical severity of arthritis was graded according to a published scoring method. ${ }^{15}{ }^{16}$ All the mice were observed for at least 90 days after the first immunisation.

\section{Enzyme linked immunosorbent assay (ELISA)}

The reactivity of serum samples obtained from the immunised mice for the CILP-MBP proteins was determined by ELISA as previously described. ${ }^{13}$ Briefly, each well of a multititre plate (Cook; Dynatech, Alexandria, VA) was coated with $2 \mu \mathrm{g}$ per well of CILP-MBP or bovine type II collagen in $100 \mathrm{mM}$ carbonate buffer (pH 9.4) at $4^{\circ} \mathrm{C}$ overnight. Thereafter, the plates were washed five times in phosphate buffered saline (PBS, pH 7.4) containing 0.05\% Tween-20 (PBST), and incubated in PBST containing 3\% bovine serum albumin (BSA) for 1 hour at room temperature, and then washed again. To absorb reactivity against bacterial proteins and the fusion partner, the murine serum samples were preincubated in PBST-3\% BSA with bacterial lysate containing non-recombinant pMAL-eHis products, and then incubated in the coated wells in triplicate for 16 hours at $4^{\circ} \mathrm{C}$. After washing, the plates were incubated for 1 hour with horseradish peroxidase conjugated antimouse IgG antibodies (Zymed Laboratories, Inc), washed again, and allowed to react with an $o$-phenylenediamine of a substrate of horseradish peroxidase. The reaction was terminated by addition of $9 \mathrm{~N} \mathrm{H}_{2} \mathrm{SO}_{4}$, and absorbance at $492 \mathrm{~nm}$ was measured by Titertek Multiscan (Biorad). For each sample, the value of the optical density (OD) for MBP was subtracted from the OD for the CILP-MBP proteins to obtain OD values for CILP (OD sample). The reactivity of each serum with the CILP proteins was expressed in units according to the following formula: binding units of samples $=$ (OD sample/(mean OD of normal sera +3 SD of normal sera) $) \times 100$. Normal serum samples were obtained from non-treated mice.

\section{Cellular proliferation to the fragments of CILP}

Mononuclear cells were separated from the mice spleens and draining lymph node cells by a standard gradient centrifugation method with Ficoll-Paque (Pharmacia Biotech AB, Sweden). The mononuclear cells were maintained in RPMI medium supplemented with heat inactivated $10 \%$ fetal calf serum. Proliferative responses of the mononuclear cells against the CILP-MBP proteins or MBP alone were quantified by the ${ }^{3} \mathrm{H}$ labelled thymidine uptake assay, as described previously. ${ }^{12}$ The cell proliferation was used to calculate a stimulation index (SI) using the following formula: $\mathrm{SI}=(\mathrm{cpm}$ stimulated by the fusion protein $) /(\mathrm{cpm}$ stimulated by MBP of the fusion partner alone). All experiments were performed in triplicate.

\section{Histopathological analysis}

At the end of the study the mice were killed and their hind feet were removed, fixed in $10 \%$ formalin, and decalcified for 24 hours. Subsequently, they were dehydrated in graded alcohol concentrations, and then processed for embedding in paraffin wax. Each section throughout the joint was cut at $6 \mu \mathrm{m}$ on a microtome and stained with haematoxylin and eosin or safranin $\mathrm{O}$.

\section{NTPPHase activity}

The enzyme activities in the serum samples of the mice were determined as described previously. ${ }^{17}$ Briefly, $10 \mu \mathrm{l}$ of serum sample diluted in $90 \mu \mathrm{l}$ of $10 \mathrm{mM}$ Tris-HCl buffer ( $\mathrm{pH} 7.8$ ) was mixed with an equal volume of $2 \mathrm{mM}$ thymidine monophosphate $p$-nitrophenyl ester (Sigma Aldrich) in $50 \mathrm{mM}$ sodium carbonate buffer $(\mathrm{pH} 9.8)$. Then the solution was incubated for 1 hour at $37^{\circ} \mathrm{C}$. The reaction was stopped by addition of $800 \mu \mathrm{l} 0.1 \mathrm{~N} \mathrm{NaOH}$, and absorbance was determined at $410 \mathrm{~nm}$. All measurements were done in duplicate.

\section{Radiographic analysis}

Conventional radiographs were obtained on the day on which clinical symptoms appeared (day 21 ) and at a later stage (day 100) using $x$ rays (Hitachi Co, Japan) at $2 \mathrm{~mA}$ and $35 \mathrm{kV}$ for $100 \mathrm{~ms}$, while the mice were under anaesthesia.

\section{Statistical analysis}

Results were analysed by Bonferroni/Dunn Student's $t$ test. All statistical analyses were performed using personal 

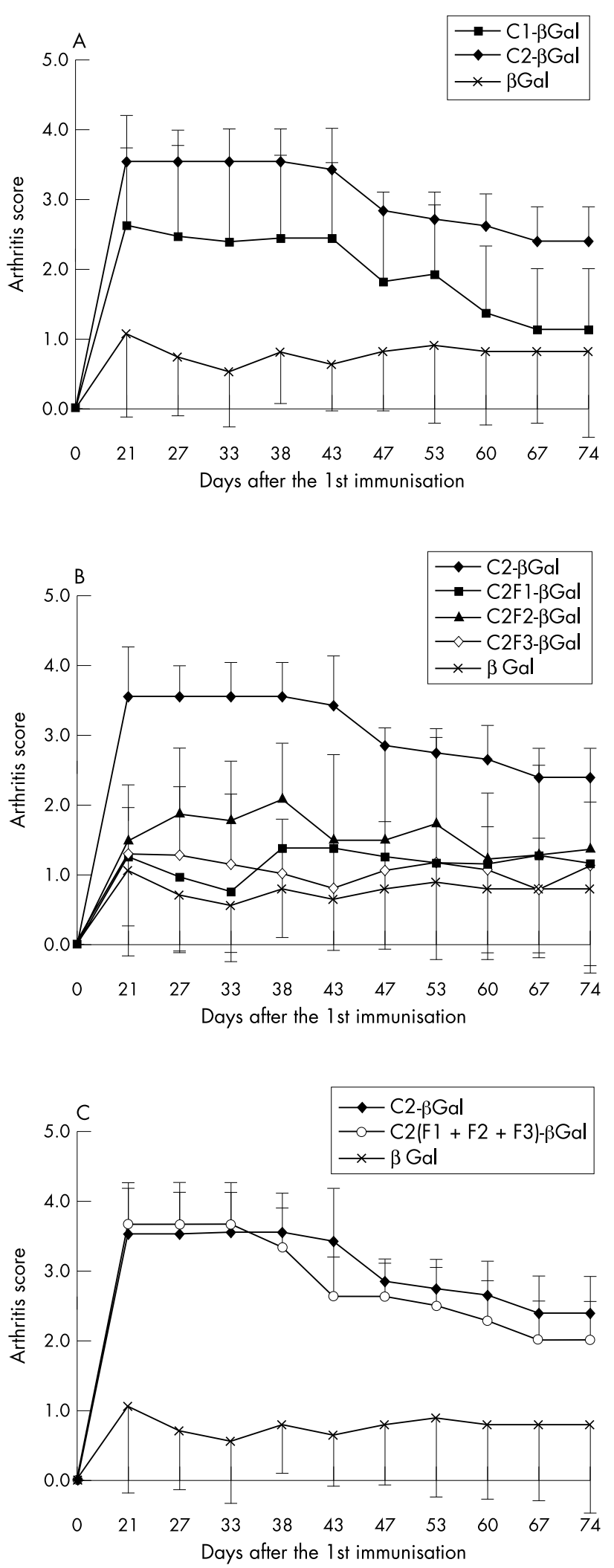

Figure 2 Arthritis developed by the immunisation of CILP proteins. (A) Arthritis developed by immunisation with C1- $\beta$ Gal, C2- $\beta$ Gal, or $\beta$ Gal alone as a control. The second immunisation was performed on the 14th day after the first immunisation. Error bars show mean (SD). (B) Arthritis developed by immunisation with $C 2-\beta \mathrm{Gal}, \mathrm{C} 2 \mathrm{~F} 1-\beta \mathrm{Gal}, \mathrm{C} 2 \mathrm{~F} 2-\beta \mathrm{Gal}$, C2F3- $\beta$ Gal, or $\beta$ Gal alone as a control. (C) Arthritis developed by immunisation with $C 2-\beta \mathrm{Gal}$, mixture of $C 2 \mathrm{~F} 1-\beta \mathrm{Gal}, \mathrm{C} 2 \mathrm{~F} 2-\beta \mathrm{Gal}$, and C2F3- $\beta \mathrm{Gal}$, or $\beta \mathrm{Gal}$ alone as control. computer based statistical software. Values are shown as mean (SD).

\section{RESULTS}

\section{Expression of recombinant CILP fusion proteins}

According to the reported nucleotide sequence of human CILP, ${ }^{9}$ we prepared recombinant CILP proteins (fig 1). Specifically, in addition to the recombinant CILP proteins fused with $\beta$ Gal (C1- $\beta$ Gal, $C 2-\beta G a l, C 2 F 1-\beta G a l, C 2 F 2-\beta G a l$, and $\mathrm{C} 2 \mathrm{~F} 3-\beta \mathrm{Gal}$ ), as described in our previous study, ${ }^{12}$ here we additionally prepared the same panel of recombinant CILP proteins, which were identical but fused with MBP (Cl-MBP, C2-MBP, C2F1-MBP, C2F2-MBP, and C2F3-MBP, fig 1B). This enabled us to detect immune reactions to CILP in mice immunised with the CILP- $\beta$ Gal proteins, avoiding detection of immune reaction to $\beta \mathrm{Gal}$. Each of the produced and purified fusion proteins showed a single band with its expected molecular weight by SDS-PAGE separation (fig $1 \mathrm{~B}$ and data not shown). Thus they were considered to be of sufficient quality to use in the following experiments.

\section{Arthritogenicity of the recombinant CILP proteins}

We previously demonstrated the arthritogenicity of CILP by immunising mice with recombinant CILP proteins. Extending the study, we here investigated whether dominant arthritogenic epitope(s) exist or not. Specifically, we immunised C57BL/6 mice with C1- $\beta$ Gal, C2- $\beta$ Gal, and $\beta$ Gal alone separately and evaluated the occurrence of arthritis in each group. We found that the $\mathrm{C} 2$ region was more potent in inducing arthritis than the $\mathrm{Cl}$ region (fig 2A). The arthritis score provided by the $\mathrm{C} 2-\beta \mathrm{Gal}$ immunisation was nearly equal to that obtained by immunisation of the $\mathrm{C} 1-\beta \mathrm{Gal} / \mathrm{C} 2-$ $\beta$ Gal mixture (data not shown). Thus we concluded that major arthritogenic epitope(s) existed in the $\mathrm{C} 2$ region.

Next, we tried to identify the arthritogenic epitope(s) in the C2 region. Specifically, we immunised mice with C2Fl$\beta \mathrm{Gal}, \mathrm{C} 2 \mathrm{~F} 2-\beta \mathrm{Gal}$, and C2F3- $\beta \mathrm{Gal}$ separately and evaluated arthritis. Figure $2 \mathrm{~B}$ shows that the arthritis score obtained by immunisation of each of the three fusions was much lower than that obtained by $\mathrm{C} 2-\beta \mathrm{Gal}$ immunisation, even though the arthritis score of the $\mathrm{C} 2 \mathrm{~F} 2-\beta \mathrm{Gal}$ immunised mice was significantly higher than that of the $\beta G a l$ immunised mice as a negative control. The arthritis scores of the C2Fl- $\beta$ Gal or C2F3- $\beta$ Gal immunised mice were similar to that of the negative control (fig 2B). This indicates that multiple epitopes in the $\mathrm{C} 2$ region are required for development of the arthritis. To confirm this, we immunised mice with a mixture of C2F1- $\beta$ Gal, C2F2- $\beta$ Gal, and C2F3- $\beta$ Gal and compared the arthritis scores with that of the $\mathrm{C} 2-\beta \mathrm{Gal}$ immunised mice. Figure $2 \mathrm{C}$ shows that the mice immunised with the mixture developed arthritis with a score which was comparable with that of the $\mathrm{C} 2-\beta \mathrm{Gal}$ immunised mice.

\section{T cell proliferative response against CILP fragments} We investigated $\mathrm{T}$ cell epitope distribution on CILP in these arthritic mice as follows. The proliferative response of spleen cells from non-treated or immunised mice to all five fragments was measured by the $\left[{ }^{3} \mathrm{H}\right]$ thymidine incorporation assay. To avoid the effects of $\beta \mathrm{Gal}$, we used MBP fusions as detecting antigens. As a result, spleen cells from the C1- $\beta \mathrm{Gal}$ immunised mice showed a proliferative response to both $\mathrm{Cl}$ MBP and C2-MBP (fig 3A). Similarly, spleen cells from the C2- $\beta$ Gal immunised mice showed a proliferative response to both $\mathrm{C} 1-\mathrm{MBP}$ and $\mathrm{C} 2-\mathrm{MBP}$ (fig 3B). It thus was confirmed at a cellular level that the immune response to the $\mathrm{Cl}$ region spread to the C2 region and vice versa. Interestingly, the C2$\beta G$ al immunised mice showed a much stronger proliferative response against $\mathrm{C} 2-\mathrm{MBP}$ than that against $\mathrm{Cl}-\mathrm{MBP}$ in the $\mathrm{Cl- \beta Gal}$ immunised mice (fig $3 \mathrm{~B}$ ). In addition, cellular 


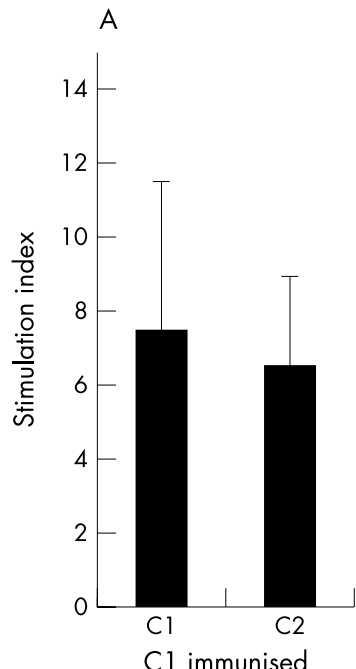

$\mathrm{Cl}$ immunised

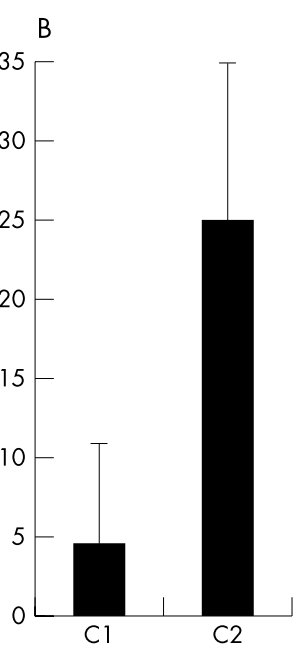

C2 immunised

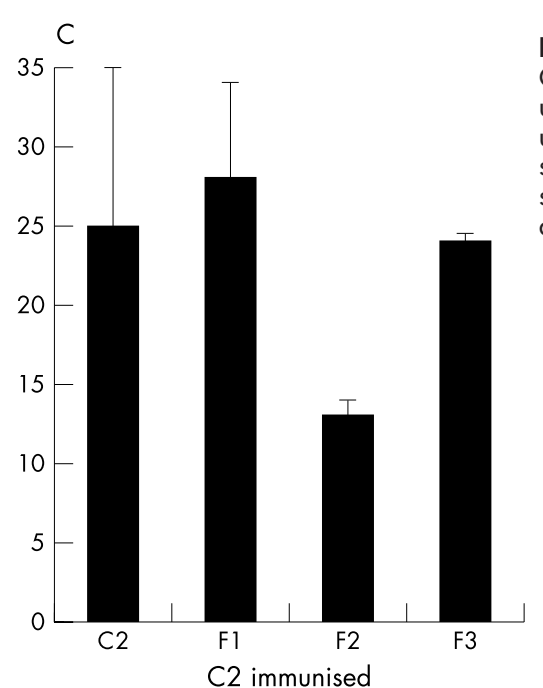

Figure 3 The cellular responses to the CILP proteins. The cell proliferation was used to calculate a stimulation index using the following formula: $\mathrm{Sl}=(\mathrm{cpm}$ stimulated by the fusion protein)/(cpm stimulated by MBP of the fusion partner alone). Error bars show mean (SD). responses to each fragment of $\mathrm{C} 2$ - that is, to $\mathrm{C} 2 \mathrm{Fl}-\mathrm{MBP}$, $\mathrm{C} 2 \mathrm{~F} 2-\mathrm{MBP}$, and $\mathrm{C} 2 \mathrm{~F} 3-\mathrm{MBP}$, were comparable with that to $\mathrm{C} 2-\mathrm{MBP}$ in the $\mathrm{C} 2$ immunised mice (fig $3 \mathrm{C}$ ).

\section{Humoral responses against CILP fragments}

Next, we investigated humoral immune responses to the CILP proteins. Firstly, we measured titres of anti-Cl and anti$\mathrm{C} 2$ antibodies both in the $\mathrm{C} 1-\beta \mathrm{Gal}$ and $\mathrm{C} 2-\beta \mathrm{Gal}$ immunised mice. C1-MBP and C2-MBP fusion proteins were used as a capturing antigen in the ELISA, to avoid detecting anti- $\beta \mathrm{Gal}$ antibodies. As a result, antibodies to both $\mathrm{Cl}$-MBP and C2MBP were detected in each of the C1- $\beta$ Gal and $C 2-\beta G a l$ immunised mouse groups (fig 4). In addition, the anti-Cl and anti-C2 antibodies did not cross react with each other (data not shown). This indicates that the immune response to the $\mathrm{Cl}$ region spread to the $\mathrm{C} 2$ region and vice versa. We further investigated the location of $\mathrm{B}$ cell epitope(s) on the $\mathrm{C} 2$ region using three small fragments of C2F1-MBP, C2F2$\mathrm{MBP}$, and C2F3-MBP, which collectively covered the whole $\mathrm{C} 2$ sequence (fig 1). As a result, we found that the $\mathrm{C} 1$ and $\mathrm{C} 2$ immunised mice were positive for antibodies against each of the three fragments; thus all the $\mathrm{C} 2 \mathrm{~F} 1, \mathrm{C} 2 \mathrm{~F} 2$, and $\mathrm{C} 2 \mathrm{~F} 3$ fragments were shown to carry B cell epitopes (data not shown).

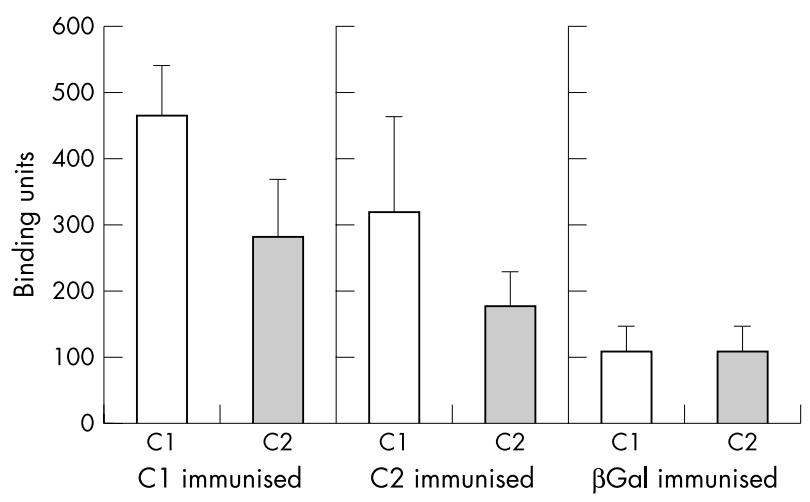

Figure 4 Antibody titres to the $\mathrm{Cl}$ and $\mathrm{C} 2$ regions in the CILP immunised mice. Pooled serum samples of each group of mice $(n=8)$ immunised either with $\mathrm{C1}-\beta \mathrm{Gal}, \mathrm{C} 2-\beta \mathrm{Gal}$, or $\beta \mathrm{Gal}$ alone were used to detect antibodies to C1-MBP and C2-MBP in an ELISA. Error bars show mean (SD).

\section{Histochemical and radiographic characterisation of the CILP-induced arthropathy}

As described in our previous study, immunisation with CILP$\beta$ Gal developed only mild arthritis in all four tested mouse strains, $^{12}$ which was in contrast with the severe erosive arthritis usually seen in CIA. To clarify further the arthritogenicity of CILP, especially in long term immunisation, we immunised mice with a mixture of $C 1-\beta$ Gal and $C 2-\beta$ Gal five times by day 70 . As a result, mild synovitis-that is, proliferation of synovial cells and infiltration of mononuclear cells (figs 5A and B) and a thin and degraded cartilage layer were seen (figs $5 \mathrm{C}$ and $\mathrm{D}$ ).

In these repeatedly immunised mice we found two interesting radiographic findings. Firstly, the CILP- $\beta$ Gal, but not $\beta \mathrm{Gal}$, immunised (control) mice developed irregular bone cortex in the metatarsals (fig 6C, arrow head). Staining with safranin $\mathrm{O}$ confirmed the irregularity and thickness of the bone cortex, as a representative case of calcaneum was shown (fig 7A). Secondly, the CILP- $\beta$ Gal, but not $\beta$ Gal, immunised mice developed calcification of the tendocalcaneus (fig 6C, arrow). This was also confirmed histochemically as mild (fig 7B). Further, irregular bone formation was also seen (fig 7C).

Pyrophosphate generated by NTPPHase, possibly including that of CILP/NTPPHase, is reported to be a major inhibitor of calcification. $^{10}{ }^{18-21}$ Therefore, we suggested that the NTPPHase activity of putative murine CILP in the human CILP immunised mice was impaired by an immune reaction, resulting in the calcification. To explore this hypothesis, we measured NTPPHase activity in the serum samples of the mice immunised repeatedly with $\mathrm{Cl} / \mathrm{C} 2$. Figure 8 shows that NTPPHase-specific activities were decreased in the sera of the mice significantly, compared with non-treated mice or mice repeatedly injected with $\beta \mathrm{Gal}$ alone.

\section{DISCUSSION}

Our findings on CILP-induced arthritis in mice can be summarised as follows: firstly, the arthritis caused by the immunisation of CILP was long lasting but mild. This was seen both in mice receiving a single immunisation and in mice repeatedly immunised (data not shown). Secondly, multiple arthritogenic epitopes in the $\mathrm{C} 2$ region were required for development of the arthritis. Thirdly, immunisation of the $\mathrm{C} 1$ protein developed an immune reaction to the $\mathrm{C} 2$ region and vice versa, indicating development of autoimmunity to mouse CILP, which is supposed to exist but has yet not been 

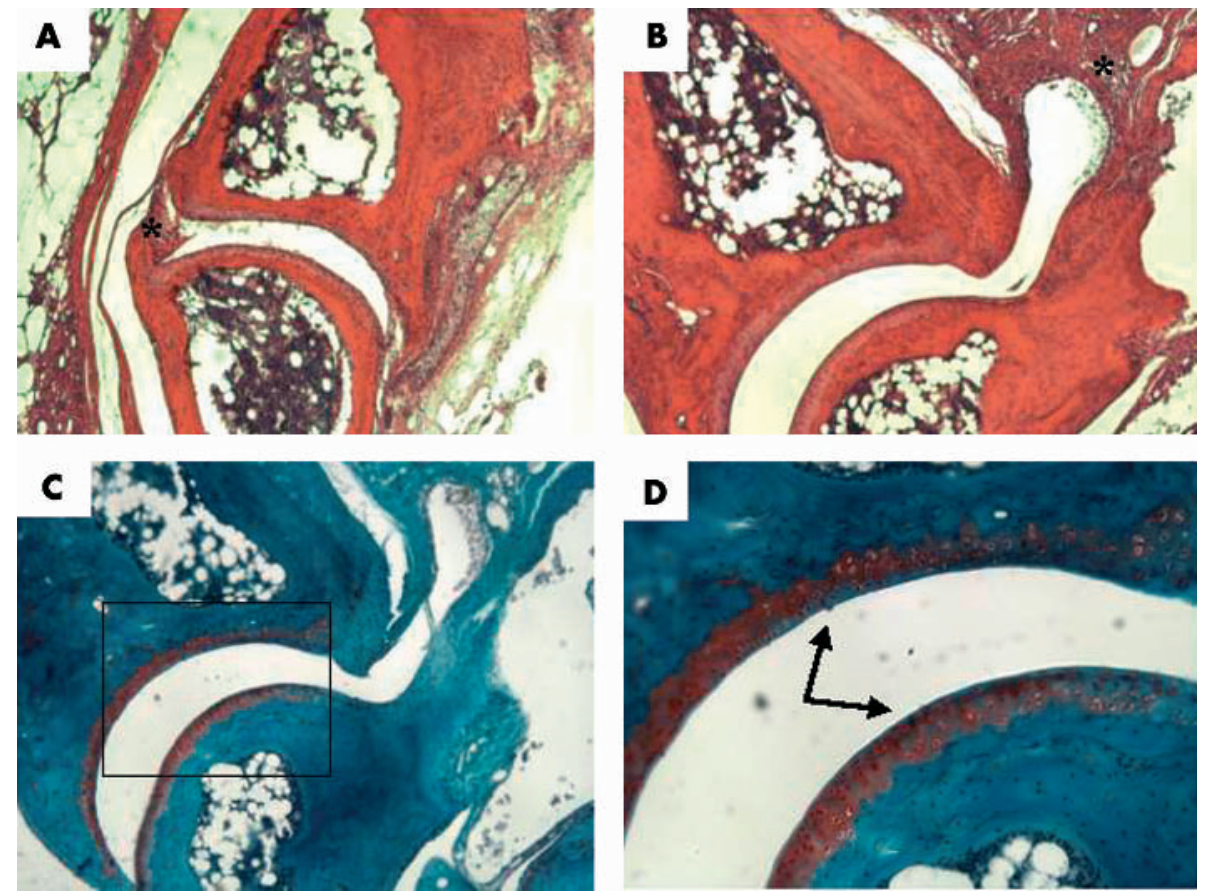

Figure 5 Histological analysis of the immunised paw by safranin $\mathrm{O}$ staining. Proliferation of the synovial tissue with mild inflammatory cell infiltration was seen (indicated by asterisks) in the midtarsal joint (A) and the ankle joint (B). Surface irregularity and cartilage degeneration are seen in the affected ankle joint (C). Magnified view of the rectangular area of (C) is shown in (D).
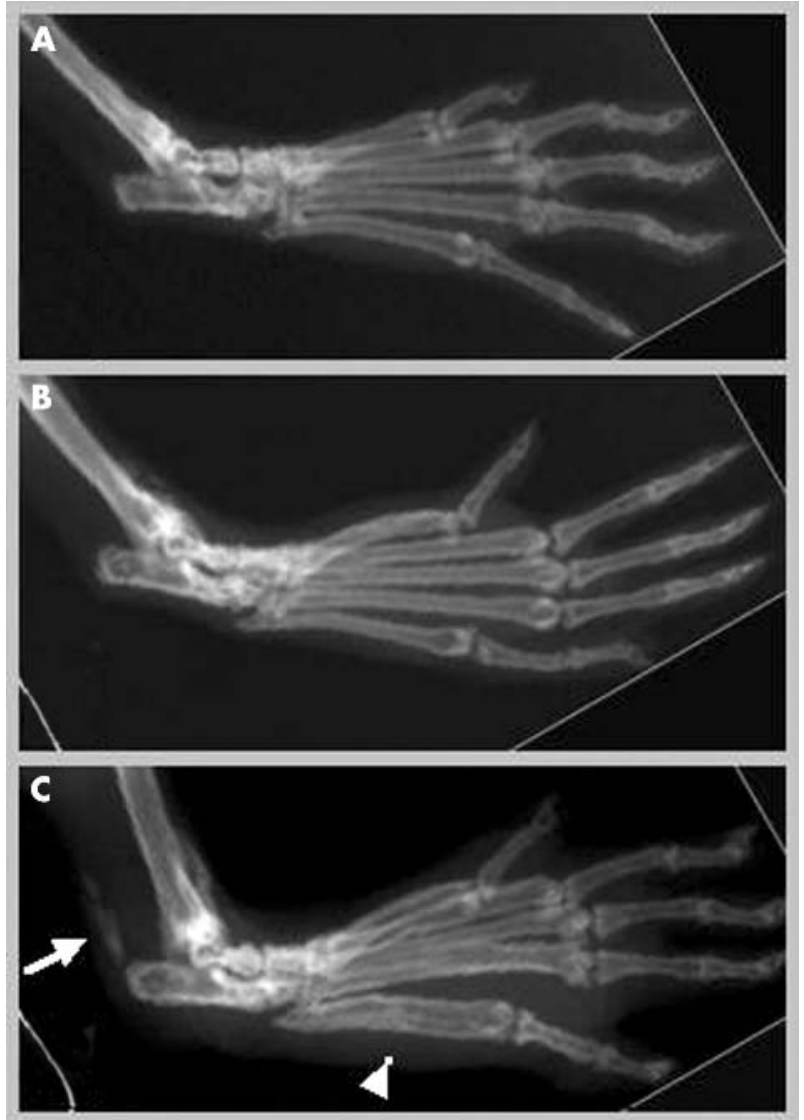

Figure 6 Radiographic findings in the CILP immunised mice. (A) Nontreated mouse; (B) $\beta$ Gal immunised mouse; $(C)$ mouse immunised with a mixture of $C 1-\beta \mathrm{Gal}$ and $C 2-\beta \mathrm{Gal}$. Irregular thickness of the bone cortex (arrow head) and calcification of the tendocalcaneus (arrow) were seen. identified. Fourthly, despite the mildness of the arthritis, calcification of the tendocalcaneus and irregularity of the bone cortex were seen. The decreased NTPPHase activity demonstrated here might be involved in the ectopic calcification.

On the first and second points, studies of animals immunised with joint related antigens have provided some clues to potential mechanisms for antigen mediated arthritis/ arthropathy. The properties of such arthritis/arthropathy would depend on individual antigens, even though they are categorised as cartilage-specific. In the case of major components of cartilage-for example, immunisation of type II collagen, severe destructive arthritis develops. ${ }^{1222}$ Similarly, proteoglycan induced severe arthritis. ${ }^{45}$ However, the arthritogenic nature of minor non-collagenous components has been rather unclear. As described previously, immunisation of mice with HC gp39 causes the development of moderate arthritis, ${ }^{6}$ whereas immunisation with YKL-39 develops mild arthritis.

We previously reported that immunisation of CILP produced relatively mild but longlasting arthritis. ${ }^{12}$ In this study we performed repeated immunisation of CILP, but the severity of the arthritis did not change compared with that of mice receiving a single immunisation. So the arthritogenicity of CILP appeared to be much weaker than type II collagen or aggrecan, immunisation of which caused severe arthritis to develop in mice. ${ }^{3}$ Interestingly, dominant arthritogenic epitopes are documented in the cases of CIA and aggrecaninduced arthritis. ${ }^{23}$ We therefore first tried to identify such dominant arthritogenic epitopes in CILP. As shown here, the severity of $\mathrm{C} 2$ immunised mice is similar to that of $\mathrm{Cl} / \mathrm{C} 2$ immunised mice, and higher than that of $\mathrm{Cl}$ immunised mice (fig 2A). Thus the $\mathrm{C} 2$ region alone carries major arthritogenic epitopes. However, each of the separate $\mathrm{C} 2 \mathrm{~F} 1, \mathrm{C} 2 \mathrm{~F} 2$, and C2F3 fragments did not show such arthritogenicity, although a mixture of $\mathrm{C} 2 \mathrm{~F} 1, \mathrm{C} 2 \mathrm{~F} 2$, and $\mathrm{C} 2 \mathrm{~F} 3$ caused arthritis similar to that of the $\mathrm{C} 2$ immunised mice (figs $2 \mathrm{~B}$ and $\mathrm{C}$ ). This indicates that multiple epitopes are involved in the pathogenic immune 

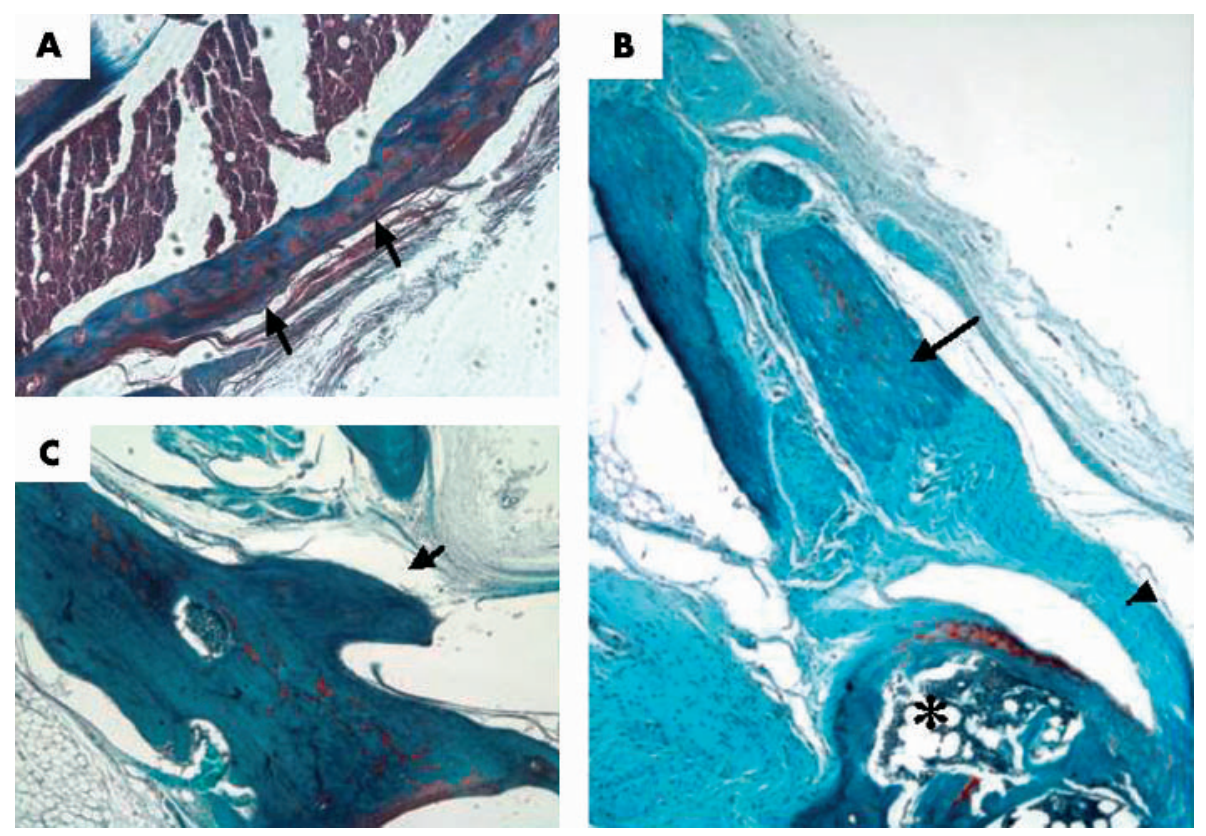

Figure 7 Histological manifestations of the immunised paw stained by safranin O. (A) The metatarsal cortex showed irregular thickness (arrows). (B) Calcification was developed within the calcaneal tendon (arrow), and the arrangement of tendon fibres was irregular and redundant (arrowhead). Asterisk shows the tip of the calcaneus. (C) Bone marrow was filled with osteal tissue and an osteal projection was found in the front of the lower tibia (arrow).

reaction in this model. Together with the reports on CIA and aggrecan-induced arthritis, ${ }^{13}$ immunodominant epitopes may be needed to produce severe destructive arthritis. Further, the cellular responses to each of the fragments $\mathrm{C} 2 \mathrm{~F} 1, \mathrm{C} 2 \mathrm{~F} 2$, and $\mathrm{C} 2 \mathrm{~F} 3$ were comparable with that to $\mathrm{C} 2$. This indicates that $\mathrm{C} 2 \mathrm{~F} 1, \mathrm{C} 2 \mathrm{~F} 2$, and $\mathrm{C} 2 \mathrm{~F} 3$ each carry immunodominant epitope(s), and thus immunodominant epitopes would be different from the arthritogenic epitopes.

On the third point, immunisation of $\mathrm{Cl}$ alone or $\mathrm{C} 2$ alone led to an immune reaction to both $\mathrm{Cl}$ and $\mathrm{C} 2$. As the generated anti-Cl antibodies did not react with $\mathrm{C} 2$ and vice versa (data not shown), the immune reactions to $\mathrm{C} 1$ and $\mathrm{C} 2$ were not cross reactive. Thus we should consider the involvement of a third molecule that intervenes between $\mathrm{Cl}$ and C2. An important possible candidate might be a mouse CILP molecule. Even though the protein has not been identified, its reference sequence supported by expressed sequence tags evidence was presented recently (XP-146393, GI: 20864514). According to the reference sequence, the putative mouse CILP molecule has about $50 \%$ amino acid sequence identity with the human CILP molecule (data not shown). Therefore,

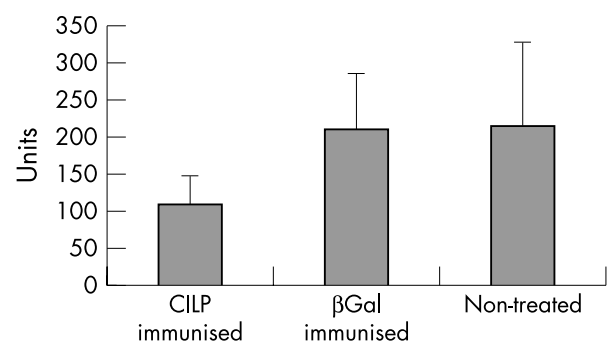

Figure 8 NTPPHase activity in the sera of mice immunised with CILP proteins. Mice were immunised with the mixture of $\mathrm{Cl} / \mathrm{C} 2$ with FCA followed four times by a booster immunisation over a period of 70 days. Control mice received $\beta G$ al and FCA with the same protocol. Error bars show the mean (SD). NTPPHase-specific activities were decreased in the sera of the mice significantly compared with non-treated mice or mice repeatedly injected with $\beta$ Gal alone $(p<0.05)$. immunisation of $\mathrm{C} 2$ would generate autoimmunity to putative mouse CILP, and the observed anti-Cl immune reaction would be part of the immune reaction to the whole molecule of mouse CILP. This scenario can be applied to an explanation for the fourth finding as follows.

We found calcification of the tendocalcaneus and irregularity of the bone cortex after repeated immunisation of CILP. The $\mathrm{COOH}$ terminus of the CILP molecule was very similar (90\%) to a porcine NTPPHase. ${ }^{9}$ The NTPPHase generates inorganic pyrophosphate (PPi) by hydrolysing extracellular nucleoside triphosphate (ATP), and PPi is a major inhibitor in calcification, such as soft tissue calcification and bone mineralisation. ${ }^{18}$ In fact, deficiency of PC-1, one of the PPigenerating NTPPHases, causes ankylosis in mice $\mathrm{e}^{23-26}$ and infantile arterial calcification with periarticular calcification. ${ }^{27}$ We may thus speculate that the autoimmunity to the putative mouse CILP molecule, which might spread to other NTPPHases, reduced the NTPPHase activity. In addition, possibly the autoantibody against CILP/NTPPH indirectly affects the PPi metabolism by, for example, a negative feedback mechanism at the levels either of extracellular ATP accumulation or the NTPPHase, or by affecting the function of other pyrophosphate related proteins such as ank. ${ }^{28}$ However, because the NTPPHase activity of CILP is still controversial, $^{29}$ the mechanism should be further investigated. For example, it would be helpful to detect the functional activity of anti-CILP antibody or sera in directly blocking the NTPPHase activity.

In conclusion, we demonstrated that autoimmunity to CILP causes mild polyarthritis to develop, and when the antigen stimulation is repeated, ectopic calcification on tendons and abnormal mineralisation of the bone cortex are induced in the immunised mice. The overall clinical features of the arthropathy may be determined by a balance between the antigenic potential and the functional loss of the sensitised cartilage related antigens.

\section{ACKNOWLEDGEMENTS}

This work was supported in part by grants in aid from the Ministry of Health, Labour and Welfare, Japan; the Ministry of Education, 
Culture, Sports, Science, and Technology, Japan; and the Japan Rheumatism Foundation.

\section{Authors' affiliations}

Z Yao, H Nakamura, K Masuko-Hongo, M Suzuki-Kurokawa,

K Nishioka, T Kato, Arthritis Research Centre, Institute of Medical Science, St Marianna University School of Medicine, 2-16-1 Sugao, Miyamae-ku, Kawasaki, Kanagawa, Japan

\section{REFERENCES}

1 Myers LK, Rosloniec EF, Cremer MA, Kang AH. Collagen-induced arthritis, an animal model of autoimmunity. Life Sci 1997;61:1861-78.

2 Cremer MA, Rosloniec EF, Kang AH. The cartilage collagens: a review of their structure, organization, and role in the pathogenesis of experimental arthritis in animals and in human rheumatic disease. I Mol Med 1998:76:275-88.

3 Zhang Y, Guerassimov A, Leroux JY, Cartman A, Webber C, Lalic R, de Miguel $\mathrm{E}$, et al. Arthritis induced by proteoglycan aggrecan $\mathrm{G} 1$ domain in $\mathrm{BALB} / \mathrm{c}$ mice. Evidence for T cell involvement and the immunosuppressive influence of keratan sulfate on recognition of T and B cell epitopes. J Clin Invest $1998 ; 101: 1678-86$

4 Mikecz K, Glant TT, Poole AR. Immunity to cartilage proteoglycans in BALB/c mice with progressive polyarthritis and ankylosing spondylitis induced by injection of human cartilage proteoglycan. Arthritis Rheum 1987;30:306-18.

5 Glant $\Pi$, Mikecz K, Arzoumanian A, Poole AR. Proteoglycan-induced arthritis in $B A L B / c$ mice. Clinical features and histopathology. Arthritis Rheum 1987;30:201-12.

6 Verheijden GF, Rijnders AW, Bos E, Coenen-de Roo CJ, van Staveren CJ, Miltenburg AM, et al. Human cartilage glycoprotein-39 as a candidate autoantigen in rheumatoid arthritis. Arthritis Rheum 1997:40:1115-25.

7 Sakata M, Masuko-Hongo K, Tsuruha J, Sekine T, Nakamura H, Takigawa M, et al. YKL-39, a human cartilage-related protein, induces arthritis in mice. Clin Exp Rheumatol 2002;20:343-50

8 Lorenzo P, Bayliss MT, Heinegard D. A novel cartilage protein (ClLP) present in the mid-zone of human articular cartilage increases with age. J Biol Chem 1998;273:23463-8

9 Lorenzo $P, N$ Neame $P$, Sommarin $Y$, Heinegard D. Cloning and deduced amino acid sequence of a novel cartilage protein (CILP) identifies a proform including a nucleotide pyrophosphohydrolase. J Biol Chem 1998;273:23469-75.

10 Hirose J, Masuda I, Ryan LM. Expression of cartilage intermediate layer protein/nucleotide pyrophosphohydrolase parallels the production of extracellular inorganic pyrophosphate in response to growth factors and with aging. Arthritis Rheum 2000:43:2703-11.

11 Masuda I, lyama KI, Halligan BD, Barbieri JT, Haas AL, McCarty DJ, et al. Variations in site and levels of expression of chondrocyte nucleotide pyrophosphohydrolase with aging. J Bone Miner Res 2001;16:868-75.

12 Tsuruha J, Masuko-Hongo K, Kato T, Sakata M, Nakamura H, Nishioka K. Implication of cartilage intermediate layer protein in cartilage destruction in subsets of patients with osteoarthritis and rheumatoid arthritis. Arthritis Rheum $2001 ; 44: 838-45$
13 Matsui T, Kurokawa M, Kobata T, Oki S, Azuma M, Tohma S, et al. Autoantibodies to T cell costimulatory molecules in systemic autoimmune diseases. J Immunol 1999; 162:4328-35.

14 Yu X, Matsui T, Otsuka M, Sekine T, Yamamoto K, Nishioka K, et al. Anti-CD69 autoantibodies cross-react with low density lipoprotein receptorrelated protein 2 in systemic autoimmune diseases. J Immunol 2001;166:1360-9.

15 Courtenay JS, Dallman MJ, Dayan AD, Martin A, Mosedale B. Immunisation against heterologous type II collagen induces arthritis in mice. Nature 1980;283(5748):666-8.

16 Terato K, Hasty KA, Reife RA, Cremer MA, Kang AH, Stuart JM. Induction of arthritis with monoclonal antibodies to collagen. J Immunol 1992; 148:2103-8

17 Cardenal A, Masuda I, Haas AL, Ono W, McCarty DJ. Identification of a nucleotide pyrophosphohydrolase from articular tissues in human serum. Arthritis Rheum 1996;39:252-6.

18 Terkeltaub RA. Inorganic pyrophosphate generation and disposition in pathophysiology. Am J Physiol Cell Physiol 2001;281:C1-11.

19 Huang R, Rosenbach M, Vaughn R, Provvedini D, Rebbe N, Hickman S, et al. Expression of the murine plasma cell nucleotide pyrophosphohydrolase PC-1 is shared by human liver, bone, and cartilage cells. Regulation of PC-1 expression in osteosarcoma cells by transforming growth factor-beta. J Clin Invest 1994;94:560-7.

20 Caswell AM, Ali SY, Russell RG. Nucleoside triphosphate pyrophosphatase of rabbit matrix vesicles, a mechanism for the generation of inorganic pyrophosphate in epiphyseal cartilage. Biochim Biophys Acta 1987;924:276-83

21 Caswell AM, Russell RG. Evidence that ecto-nucleoside-triphosphate pyrophosphatase serves in the generation of extracellular inorganic pyrophosphate in human bone and articular cartilage. Biochim Biophys Acta 1988;966:310-17.

22 Moder KG, Nabozny GH, Luthra HS, David CS. Immunogenetics of collagen induced arthritis in mice: a model for human polyarthritis. Reg Immunol 1992;4:305-13.

23 Okawa A, Nakamura I, Goto S, Moriya H, Nakamura Y, Ikegawa S. Mutation in NPPS in a mouse model of ossification of the posterior longitudinal ligament of the spine. Nat Genet 1998;19:271-3.

24 Nakamura I, Ikegawa S, Okawa A, Okuda S, Koshizuka Y, Kawaguchi H, et al. Association of the human NPPS gene with ossification of the posterior longitudinal ligament of the spine (OPLL). Hum Genet 1999;104:492-7.

25 Sakamoto M, Hosoda Y, Kojimahara K, Yamazaki T, Yoshimura Y. Arthritis and ankylosis in twy mice with hereditary multiple osteochondral lesions: with special reference to calcium deposition. Pathol Int 1994;44:420-7.

26 Hosoda Y, Yoshimura Y, Higaki S. A new breed of mouse showing multiple osteochondral lesions-twy mouse. Ryumachi 1981;21(suppl):157-64.

27 Rutsch F, Vaingankar S, Johnson K, Goldfine I, Maddux B, Schauerte P, et al. PC-1 nucleoside triphosphate pyrophosphohydrolase deficiency in idiopathic infantile arterial calcification. Am J Pathol 2001;158:543-54.

28 Ho A, Johnson M, Kingsley D. Role of the mouse ank gene in control of tissue calcification and arthritis. Science 2000;289:265-70.

29 Masuda I, Hirose J. Animal models of pathologic calcification. Curr Opin Rheumatol 2002; 14:287-91. 